\title{
Data-informed decision-making for life-saving commodities investments in Malawi: A qualitative case study
}

\author{
Bennett Nemser ${ }^{1,2}$, Kyaw Aung ${ }^{3}$, Mildred Mushamba ${ }^{3}$, Samuel Chirwa ${ }^{3}$, \\ Diana Sera ${ }^{1}$, Owen Chikhwaza ${ }^{4}$, Fannie Kachale ${ }^{4}$ \\ Date Received: 29-Nov-2017 \\ Revision Received: 24-Jan-2018 \\ Date Accepted: 18-Feb-2018 \\ Correspondence: \\ Bennett Nemser \\ (bnemser@gmail.com) \\ 2. University of the Western Cape, South Africa \\ 3. UNICEF Country Office, Malawi \\ 4. Ministry of Health, Malawi

\section{Background}

\section{Abstract}

During the last 15 years, Malawi has made remarkable progress in reducing child mortality. However, maternal and newborn mortality remains persistently high. To help address these entrenched challenges, the Reproductive, Maternal, Newborn and Child Health (RMNCH) Trust Fund provided short-term catalytic financing of \$11.5 million (2013-2016) to support country plans to advance the RMNCH and commodity agenda.

Objectives

(1) To document how Malawi (ministries, partners, working groups) used evidence to inform decision-making and RMNCH investments, (2) To identify barriers to utilizing information and evidence in the planning and prioritization process at national and sub-national levels, and (3) To assess the utility of the RMNCH Landscape Synthesis, which uses existing information to review lifesaving RMNCH commodities and services.

Methods

This was a qualitative case study utilizing a Rapid Appraisal (RA) approach, where semi-structured interviews were conducted with staff members from UN agencies, development partners and the Ministry of Health $(\mathrm{MoH})$ at national and district level. The analysis enlists a framework approach for manual qualitative content analysis.

Results

Led by the MoH, the RMNCH Trust Fund grant proposal utilized an evidence-based and equity-focused process for prioritization of investments. Data-informed decision-making permeates similar commodity-focused working groups. However, common health information system (HIS) weaknesses, such as data quality and collection burden, persist and are more prevalent at district-level. The collation of evidence in the RMNCH Landscape Synthesis was a useful and sustainable tool to support planning.

Conclusions

The evidence-based, equity-focused decision-making process for the RMNCH Trust Fund proposal provides an effective model for inter-agency investment prioritization. Strengthening data-informed decision-making will require financial and political commitments to HIS and capacity building for data use, particularly at the district-level. New initiatives (e.g. Health Data Collaborative and QED Network to Improve Quality of Care) provide opportunities to further improve evidence-informed decision-making.

\section{Introduction}

Malawi has experienced steady progress in reducing underfive mortality from 234 (per 1,000 live births) to 63 from 1992 to 2015 , respectively ${ }^{1}$, an impressive $73 \%$ decline to reach the Millennium Development Goal (MDG). However, reductions in neonatal mortality have been more challenging - decreasing at a relatively slower pace of approximately $34 \%$ from 41 (per 1,000 live births) to 27 over the same 23 year period ${ }^{1}$. These rates vary widely across districts and the urban/rural divide, which may depict inequitable access to appropriate and timely health services ${ }^{1}$. In addition, maternal mortality is 439 (per 100,000 live births) ${ }^{1}$, which failed to reach the MDG target ${ }^{2}$. While institutional delivery varies widely by socioeconomic status ${ }^{3}$, on average, $91 \%$ of births are delivered in a health facility ${ }^{1}$. However, in 2013, only onethird of the facilities had recent relevant in-service training and $45 \%$ had insufficient stocks of essential medicines for delivery, such as injectable antibiotics (e.g. penicillin, gentamycin, ampicillin, or ceftriaxone) ${ }^{4}$. Inequitable access to essential services and quality of care contributes to this discrepancy between high rates of treatment seeking and

\section{relatively low mortality reductions ${ }^{2}$.}

An equity-based and data-informed approach to health investment decisions provides a constructive framework for addressing these service delivery disparities. In the context of maternal and child health, an equitable environment provides an opportunity for each woman, newborn and child to survive, thrive and reach their full potential ${ }^{5,6}$. United Nations Children's Fund (UNICEF) defines inequity as when certain groups are "unfairly deprived of the basic rights and opportunities available to others"'. Equity-based approaches focus investment on disadvantaged groups as well as the underlying factors creating the inequity. Investments in equity are both ethical and cost-effective ${ }^{8,9}$. Unfortunately, health services fail to reach the most vulnerable populations and often perpetuate socioeconomic, ethnic or gender differences $^{9-11}$. In recent years, many UN agencies and partners have adopted an equity approach to public health and international development $\mathrm{t}^{5,72-14}$.

Data-informed decision-making is "the consideration of data during program monitoring, review, planning, and improvement; advocacy; and policy development and review"15. Data-informed 

decision-making enables any level of the healthcare coordinating team, the Strategy and Coordination Team system - individual, community, facility, district, regional, (SCT) Malawi, completed multiple rounds of the RMNCH national and global - to respond to prioritized necessities". Landscape Synthesis monitoring tool (also known as the Understanding the importance of data-informed decision- RMNCH Situation Analysis $)^{20}$. The RMNCH Landscape making, the Malawi Ministry of Health published guidelines Synthesis is a relatively new monitoring tool and approach, on using evidence in health policy making ${ }^{17}$. Data-informed which can link to existing planning processes and facilitate decision-making can facilitate equity-focused health data-informed decision-making around RMNCH policy and system improvements. With disaggregated data by target investments ${ }^{20}$. Guided by the 13 UNCoLSC commoditie population, decision-makers can incorporate an equity- and recommendations, the RMNCH Landscape Synthesi based approach for national and sub-national planning uses existing information systems and expert interviews and investment prioritization. In 2013, an opportunity to review the state of commodity manufacturing, import, for Malawi to undertake an equity-based, data-informed procurement, regulation, quality control, supply and investment strategy for reproductive, maternal, newborn and utlization, to help identify in-country barriers to accessing child health (RMNCH) became available with short-term life-saving RMNCH commodities and services.

catalytic financing from the RMNCH Trust Fund. Malaw was awarded two grants from the RMNCH Trust Fund for $\$ 3.9$ million (USD) in 2013 and $\$ 7.6$ million (USD) in 201 to support country RMNCH and commodity plans. Grant the the Ministry of Health, UN agencies and development partners. Therefore, this relatively flexible financing provide an opportunity to fill needed funding gaps and potentially prioritize equitable access to RMNCH services and lifesaving commodities

Globally, the RMNCH Trust Fund began operation in 2013 to complement the UN Commission on Life Saving Commodities for Women's and Children's Health $(\mathrm{UNCoLSC})^{18}$, which emphasized 13 under-utilized, low-cost and high-impact commodities (Figure 1) across the RMNCH spectrum that could substantively reduce preventable
deaths if implemented at scale. The UNCoLSC outlined 10 recommendations (Figure 1) for addressing key health system bottlenecks, such as improving regulatory efficiency (e.g. standard treatment guidelines ${ }^{19}$ ), shaping local markets, enhancing medicine quality and safety, strengthening supply chains, improving health worker performance, generating demand, and reaching vulnerable populations. These recommendations, coupled with the 13 commodities, provide an actionable focus to help identify and address barriers to effective delivery of critical health interventions.

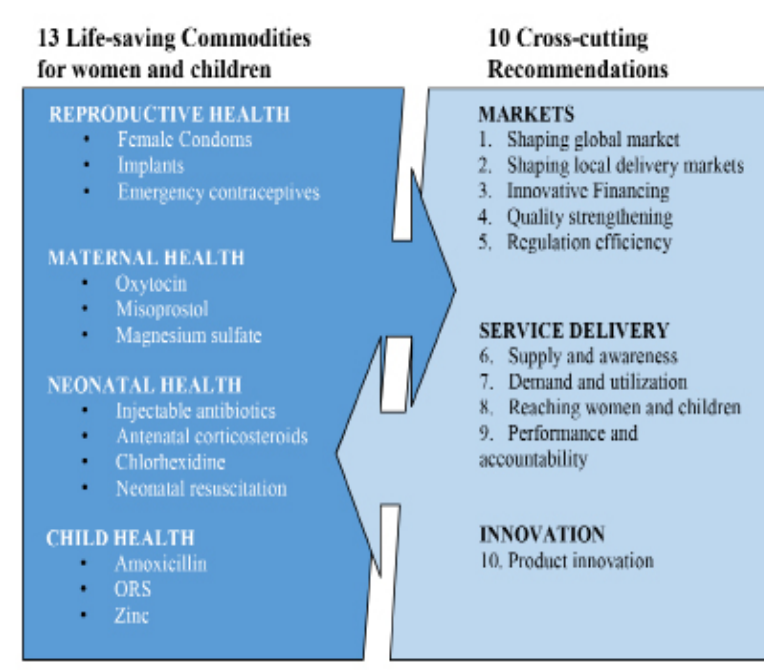

on Life-Ssuing Commodities for Women and

Children: Commissioners' Report 2012. New York, USA; 2012 .
Figure 1: UNCoLSC: 13 Commodities and 10 Recommendation

With support of the RMNCH Trust Fund and its administrative leave during the data collection time period.
With the exception of one organization, an alternative interviewee was identified from each organization where non-participation occurred. In addition, the verbal informed consent process at the start of each interview notified the interviewee of their right to refuse the interview or end
the interview at any time, but no interviewee exercised this opportunity to cancel or prematurely end the interview.

\section{Data Collection}

Interviews were conducted in Malawi over an 8-day period in July 2016. Interviews were scheduled at the convenience of the interviewee and conducted in the location selected by the interviewee, which was typically their respective office building. All interviews were conducted in English. BN MM, and SC, conducted all of the interviews with multiple enumerators present during sessions with approximately half of the interviewees. The interviewer obtained verbal informed consent from the interviewee prior to initiation of the interview. A semi-structured interview guide was utilized during each interview. Based on the knowledge and experience of interviewee, the interviewer had the autonom to delve more deeply into a specific topic or move to the next one. Different interview guides were utilized for the two primary types of interviewees national and district-level respondents. The development and use of the interview guide was an iterative process as the enumeration team in the enumeration

\section{ta Analysis}

Interview discussions were recorded as typed notes an written summaries. Interviewees were asked questions about internal activities and external partners, which presented risk of meaningful negative impact to the respondent. To promote openness, the interview was not audio recorded. Each interviewer entered written notes from the discussion into their respective password-protected computer. When multiple interviewers were present, the set of notes were compared post-interview for consistency and combined to ensure all relevant information was captured for analysis. This research enlists a framework approach for manual qualitative content analysisis $20-26$. The researchers read through the Using the a priori study objectives and experience during the Using the a priori study objectives and experience during the and developed a the rese fromers id to organize themes of the interviews. Each interview transcript was the resuls of the intervicus. Each interview transcript was annotated using Microsoft Excel software. Deveropm of typogies using Niciotions were based on the interview resuls mogped rainst the them we bremewor. Data use for phnning priorization was the andyic angle used for this sudy.

\section{Ethics}

The study required confidential interviews with respondents in various ministerial positions, UN agencies and partners. Given the nature of the questions and opinions solicited, disclosure of responses has a meaningful risk of negative impact on the respondent. All respondents were given ent prior to the interview. Each respo we informed of the study's benefits, risks, contact list and their right to stop the interview at any time. Interview notes were recorded on computers by the enumeratio team (no audio recordings). All interview notes and All interview and consent materials were presented to the National Health Science Research Committee of Malaw which gave approval prior to undertaking the study.

\section{Findings}

In regards to data-derived decision-making, four main thematic findings were recognized, including:

1. RMNCH Trust Fund investment process was governmentled and data-informed

2. Data-informed decision-making permeates other technical working groups

3. Common data challenges hamper progress and more pronounced at sub-national levels

sustained

1.RMNCH Trust Fund investment process was

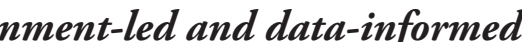

make investment decisions for the two RMNCH Trus Fund grants, the Ministry of Health established the RMNCH Committee, which was led by the Ministry of Health and included UN agencies, development partners, civil society and implementing organizations. The investment decisiondisting proess had two fundamental steps: selection of 12 districts for hivestment and selection of activities withi those 12 districts (Figure 2).

\section{Districts}

$\sqrt{ }$

Prioritized

凤

Activities
Selected

districts, each district presented t 12

analysis using quantitative and qualitative

data from health facilitics and conmunity
interviews. The Committee prioritized

complemen
interventions
nats

Fig 2: RMNCH Trust Fund investment process

To select the 12 districts for investment, the Committec used an equity-based approach to prioritize geographica reas with relatively weak health indicators. Primary impact indicators from the Health Sector Strategic Plan (HSSP) such as maternal, newborn and child mortality, were used to compare districts as well as service and commodity vailability and partner presence to facilitate implementation, among others. The indicators were collated from various xisting data sources (Table 2). 


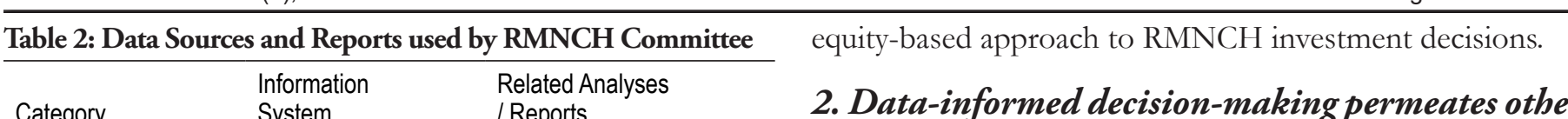

Category Related A
/ Reports

Population-
based

2. Data-informed decision-making permeates othe techical working groups

A common thread across RMNCH-related technical working groups is data-informed decision-making. In Malawi, mos essential medicines are procured and distributed through the Central Medical Store Trust (CMS I). However, multip partners manage parallel supply chain systems. The Drug and Medical Supplies Technical Working Group (DMS TWG) provides a forum for the government and partners the coordinate drug management decisions as well as related TWG wants "decisions to be evilence- acte" " The DMS W w ' as the 'Pipeline' report, which collates data from multiple

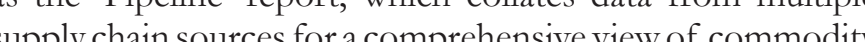
vailability at national level. When a prospective commodity ap is identifed in out-months - typically using the Pipeline gap is identifed in out-months - typically using the Pipeline Chat, the Ministry of Healt, acting as the DMS IWG Partners determine how procurementand rending shortfall. an be augmented to meet upcoming needs. For purters final decisions are made outside the DMS TWW foruts confirmation with the partners' internal teams - the decision is "left to partners to see what their budget can carry" - while fficial MoH decisions typically require endorsement from Senior Man decisions typically require endorsement from resources cannot meet the demand across commo DMS TWG prioritizes commodities and supplies with the highest impact. In particular, the essential health package (EHP) 2,27 and other "must have" commodities for hospitals and health facilities with high impact and high consurion rates, such as amoxicillin, are priotitized. In a similar fashion, when commodity storage at health facilities was identified as an issue, DMS TWG commissioned an assessment to identify the projected storage gap over the next 10 years for each facility. Infrastructure investments were made fo health facilities with the largest projected gap. In addition the Reproductive Health Commodities Sub-committee and the Reproductive Health Commodities Sub-committee and the Health Sector Strategic Plan (HSSP) undertakes similar as a team, not in isolation". In the case of HSSP, the proces is similar to the RMNCH Committee including developing a situation analysis from a broad set of data sources and incorporating district improvement plans (DIP). In Malawi, establishing broad collaboration amongst partners - led by the $\mathrm{MoH}$ - to undertake data-informed decision-making is the norm.

\section{Data challenges hamper progress and more} pronounced at sub-national levels

An array of challenges - data collection burden, processing ion, quality, timeliness, an capacity - were identified across data systems and decisionmaking processe

- Data collection burden: The incredible demand for data from health facilities creates a significant burden on health personnel. By some accounts, due to the plethora of faciliennent and partner-supported programs, health tools (i.e. 'by hand') - more than 800 indicators each month. Moreover, with most of facility-level data collected on paper forms (e.g. LMIS, DHIS2), the production and timely transport of paper to and from facilities is resource intensive. One respondent summarized this problem as a
longlasting need to identify critical data points for maternal and newborn health and make [data collection] routine

- Data Processing and Analysis: While district level health information systems have improved in recent years, the tools lack specific utility for the District Health Officer (DHO). In DHIS ${ }^{2}$, denominators for most indicators are not readily available; therefore, the DHO must export the data to Exce for proper analysis. Dashboards are limited and while the DHO can create their own dashboard, the tool is rarely used. In addition, multiple automated reports in the DHO LMIS (Supply Chain Manager software) fail to generate on
a regular basis, which occurred during one interview. At the national level, one respondent drew attention to the multiple and often uncoordinated planning processes, which led to redundant data processing and analyses.

- Data Use: The demand for and use of data is a comple and discordant effort. The high data collection burden is not matched with effective data use, which ultimately under-utilizes the health information system. Respondents rticulated that "we need to continue escalating the use of some lamented that the demand within technic working groups for processed and packaged data analysis example, fill rates and distribution performance metrics are avilab within the IMIS, but are not processed, ana and presented to the DMS TWG At sub-nationl level, DHOs send the data upwards to the national-level, but has limited capacity to provide feedback to helth facilities (outside of infrequent supervision visits or pootly attended district review meetings), which in turn weakens data capacity at facility levels. There is a perception that district, facility and community stakeholders "do not have sufficient access to data to make decisions". The DHO strugoles to maximize use of available quantitative information for the DIP process. To ameliorate this shortfall, DHOs conduct qualitative interviews and focus groups with communities; however, due to funding constraints the process often happens only once per year in one community. Limited use of available data undermines the value of health information systems and the potential of subsequent decision-making.

- Communication: From the national to the community level, effectively presenting and communicating findings from the health information systems was a perceived challenge by respondents. At the national level, access to user-friendly data presentations was a common complaint. Moreover, there is a perception that "communication is too highlevel" where advocacy and communication packages do not respond to district or community needs. Within the DHO, eport-writing skills of staff were an area for improvement. While training on data management was common, skill building around writing, presentation and communication of results was limited.

- Data quality: While not uniform, a perception of poo data quality existed for some data sources. For example, In LMIS, there is no routine audit mechanism for dat quality. Supervisor visits are held to support capacity
building and review data submissions; however, these visits Tovide commodity replenishment that is inconsistent with eartent stock status or requested quantities, which c weates ate data submissions. Within DHIS2, the quality of many RMNCH indicators is deemed insufficient for commodity quantification analyses; therefore, estimates are used.

Data timeliness: The timeliness of data reportinghas improved

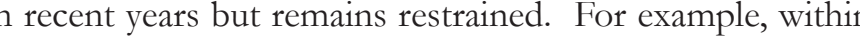
the monthly stock status reports (known as HTSS report), eporting rates increased from approximately $60 \%$ in 2013 to more than $90 \%$ in 2016 . However, if a health facility reports before the monthly deadline, but reports on only a smal (the ubmission is still considered sufficient and timely.

- Capacity: A common challenge at all levels of the health Each challenge listed above within the health infopacity. sysem (e. data collecion, andsis, use, commurication system (e.g. data collection, analysis, use, communication, ) in a been undertaken, however, high turnover has destabilized these foundational steps.

\section{RMNCH Landscape Synthesis added value and} should be sustained

The RMNCH Landscape Synthesis was considered a aluable addition to the data use and planning processes. Respondents appreciated the type of information collated and the presentation format. The breadth of information Rerrer services and commodities facilitated (e.se 作 illustrate their interconnected objectives. The approach of using avallable quantitative data complemented with expert the as an efficient use and showcase existing health information systems. The perceived

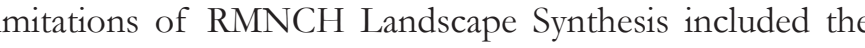
possibility of adding commodities, indicators or improving the presentation format, but most critiques focused on the sub-national data. While the RMNCH Landscape Synthesis was a useful tool for national level decision-making disaggregated district-level data was absent and thus utility at the sub-national level is minimal. Expansion of the RMNCH Landscape Synthesis to district-, facility- and communityGiven the utility of the RMNCH Iandscape Synthesis, Gise the utility of the RMNCH Landscape Synthesis, RMNCH Landscape Synthesis. Most respondents proposed integrating the RMNCH Landscape Synthesis into simila Ministry of Health dat Landscape Synthesis into similar in the Department of Planning and Policy Development However, "sustainability for next 5-10 years will depend on partnership arrangements", thus partner support would likely be needed to ensure sufficient capacity was available for the immediate transition and the longer-term.

\section{Discussion} In the last two Health Sector Strategic Plans dating back
to $2011^{2,28}$, the Malawi Ministry of Health has advocated 


\section{Linking Data Use and Quality}

Malawi is constrained by the interlocking forces of data quality and data use. The results of this study are consisten with experiences in other countries where perception of
data quality is intertwined with insufficient data use ${ }^{3441}$ For example, Nicol and colleagues ${ }^{34}$ illustrated how a lack of trust in the quality of HIV-related data source in South of trust in the quality of $\mathrm{HIV}$-related data source in South program managers down to facility managers. Data use and data quality constitute a mutually reinforcing cycle ch,38,39,42,4. $^{2}$ The perception of low data quality reduces use. Conversely, Malawi, rons Mreasonable data collection burden at sub-nationl level low analytic capacity, insufficient supervision, and lack of

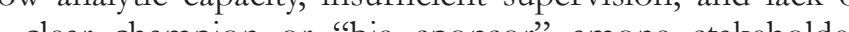
a clear champion or "big sponsor" among stakeholders stakeholders in Malawi must facilitate upward momentum within this cycle - accelerating data use to improve quality or vice versa. Even when data quality is perceived as poor or vice versa. Even when data quality is perceived as poo approach to improving quality ${ }^{34}$. Moreover, to improve dat quality and use, Harrison and Nutley ${ }^{38}$ recommend, among other activities to institutionalize data quality assurance build capacity around data analysis and interpretation, and harmonize reporting procedures across donors.

These substantive barriers and corresponding tasks will (HIS) strengthening. To this end, Malawi recently initiated a country-led collaborative approach to HIS planning and investment around a proverbial 'one country' monitoring and evaluation platform. An MOH-led monitoring and evaluation taskforce was created to guide a process of coordinated investments in HIS, rationalization of indicators, . effort to establish a national interoperable HIS $S^{45,47}$. Along with the new Health Sector Strategic Plan (HSSP)', Malaw is setting a foundation to make coordinated and substantive improvements to HIS in the coming years.

Extending utility to sub-national levels: district, facility and community

While some improvements are needed, this study illustrates that national-level planners and managers successfully use He capacity and resources to effectively institutionalize data-

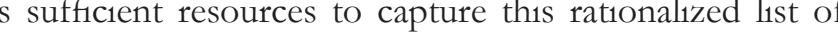
(without jeopardizing quality of care) and remove the rest. Indicator harmonization is consistent with the (ace of the Health Data Collaborative which includes membership of key partners, such as UNICEF, World Health Organization (WHO), The World Bank Group, United States Agency for Internationa Development (USAID) and the United Nations Population Fund (UNFPA).

Second, in terms of local data use, HIS improvements are typically targeted at district or regional level, which overlook local decision-makers and their data needs $s^{4,51}$. Moreover, public servants within ${ }^{2}$ found that accountability for public servants whin Malawi was constrained by limited cranizand must push efforts at the com. Therefore, to prizan local decision-makers improve social accountability and local decision-makers, improve social accountability an implementing community-level scorecards ${ }^{56}$ between he providers a com from each party and develop corresponding inpectations pans in an open and collective manner. Third, these finlings plansina apend and enhanced capacity and tools to effectively utilize information to improve helthcare delivery. This is consistent with the 2005 findings from Chaulagai and colleagues ${ }^{33}$ in Malaw where managers throughout the healthcare system had limited capacity to use data for decision-making As outlined by the Health Metrics Networl ${ }^{50}$ district-level decisionmakers need a variety of data tools and reports to consolidate information across multiple sources to effectively manage the health system. Creating harmonized districtlevel scorecards (or dashboards) - similar to the Malawis national RMNCH Scorecard ${ }^{57}$ is a productive start. Moreover, in recent years, $\mathrm{MoH}$ and partners have supported the Distric Health Performance Improvement (DHPI) ${ }^{58}$ approach in select districts, which builds capacity on local data use for equity-based bottleneck analyses and strategic planning. In a decentralized health system, extending these capabilities to all districts will improve local governance and long-term, evidence-based planning across the country.

Lastly, the results of this study indicate Malawi has taken critical steps to build a data-oriented culture within its nationa leadership. As Lorenzi and Riley ${ }^{59}$ proffer, leadership sets the pace for cultural shifts in an organization. However, like many other countries ${ }^{38,52}$, Malawi needs to improve the data use culture at sub-national levels. To this end, Malawi is undertaking a new initiative to strengthen health services with the Quality, Equity, Dignity (QED) Network to Improve

Quality of Care for Maternal, Newborn and Child Health ${ }^{60,6}$. The approach focuses on strengthening quality improvement at district and facility levels. As outlined by Green and de $\mathrm{Kock}^{62}$, QI teams undertake short cycles of improvement where they will identify urgent problems (e.g. low utilization of oxytocin), test new ways of working (e.g. ensure oxytocin's availability and readiness at frontline), measure and study the results, and sustain successful changes to operation. This approach has the potential to fundamentally change how sub-national (and national) personnel successfully use and engage with health information systems in more efficient and cost-effective ways.

National-level capacity building and sustainability of the Landscape Synthesis

One of the most frequently mentioned and most intractable challenges is capacity building for information-use acros all levels of the healthcare delivery system ${ }^{10,38,5,0,1,1,63}$. In this in Malawi $\mathrm{MoH}$ at the national level in order to sustain the RMNCH Landscape Synthesis. This is consistent with the additional support for other recent data-use initiatives, the addition support for others recent data-use initiatives, Capacity is typically provided by partners on an ongoin Capacity is typically provided by partners on an ongoing pasis, but to ensure nore sustainable operations, any governmental capacity building and handover.

Transitioning the RMNCH Landscape Synthesis to local institutions provides an opportunity to more fully adapt the tool to the Malawian context - both nationally and subnationally. The tool was originally designed to track progress for the 13 life-saving commodities as "tracers" for the wider supply chain, but various public health practitioners, such as Bhutt $^{65}$, have proposed adjustments to this list. Malawi can modify the list of commodities or related indicators to fulfill the vacillating monitoring needs of the Malawian health corticosteroids ${ }^{66}$. As advocated by Nutley and Reynolds ${ }^{39}$, engaging the data users and data producers at multiple levels of the healthcare system will ultimately increase the demand

\section{Study Limitations}

This study has several limitations. Due to the rapid assessment (RA) approach, the study team had limited time for an indepth examination of the subject matter. The short time window may have restricted interview participants based on scheduling availability, although only one organization on the interview list was not available. UNICEF provided the interview list, which may have unintentionally biased the respondent selection towards favorable opinions. No facility based personnel or community members were interviewed; therefore, the perceptions of facility or community issues were not corroborated and could present an area for further research. In addition, some questions asked were recall bias is possible. Iastly to improve openness of the recall bias is possible. Lastly, to improve openness of the interviews, which may have resulted in lost or misinterpreted

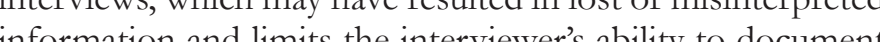
verbatim quotes. While every effort was made to instill an
作 formation about the process or partners.

\section{Conclusion}

The data-informed, equity-focused decision-making process for the RMNCH Trust Fund proposal provides an Strentive model for inter-agency investment prioritization. Strengthening data-informed decision-making will require financial and political commitments to HIS and capacity building for data use, particularly at sub-national levels. New initiatives (e.g. M\&E Taskforce / Health Data Collaborative Newbon improve data-informed decision-making.

\section{References}

National Statistical Office (NSO) [Malawi], ICF International. thelawi Demograpic and Health Survey 2015-16. Zomba, Malawi, and Rockville, Maryland, USA.; 2017. https://dhsprogram.com/pubs/pdi/ FR319/FR319.pdf.

2. Ministry of Health (MoH) [Malawi]. Malawi Health Sector Strategic Plan II 2017-2022. Lilongwe, Malawi; 2017. http://www repository/malawi/health_sector_strategic_plan_ii_030417_smt_dps. pdf.

3. UNICEF, WHO. A Decade of Tracking Progress for Maternal, Cort. Vol 6736. Geneva, Swizerland; 2015. doi:10.1016/S0140-6736(15)00519-X.

4. Ministry of Health (MoH) [Malawi], ICF International. Malawi Service Provision Assessment (MSPA) 2013-14. Lilongwe, Malawi, and dhsprogram.com/pubs/pdf/SPA20/SPA20\%255BOct-7-2015\%255D. 5amberger M, Segone M. How to Design and Manage Equityocused Evaluations. New York, USA; 2011. http://www.pol.ulaval.ca/ perfeval/upload/publication_319.pdf

6. The Global Strategy for Women's and Children's and Adolescents' Health (2016-2030): Survive, Thrive, Transform. Vol 1. New York, USA; 2015. doi:10.1017/CBO9781107415324.004.

7. Bocquenet G, Chaiban T, Cook S. The State of the World's Children 2016: A Fair Chance for Every Child. New York, USA; 2016 doi:10.18356/4fb40cfa-en.

8. United Nations Childrens Fund (UNICEF). Narrowing the Gaps: The https://www.unicef.org/publications/index_96534.html.

9. Carrera C, Azrack A, Begkoyian G, The comparative costequity-focused approach to child survival, health, and nutrition: a modelling approach. Lancet (London, England)

10. Bryce J, Requejo JH, Moulton LH, Ram M, Black RE. A commo evaluation framework for the African Health Initiative. BMC Health Serv Res. 2013;13 Suppl 2(2):S10. doi:10.1186/1472-6963-13-S2-S10 1. Victora CG, Requejo JH, Barros AJD, Countdown to 2015: Adecace 2016;387(10032):2049-2059. doi:10.1016/S0140-6736(15)00519-X. 12. FP2020 Partnership in Progress: 2013-2014. Washington, D.C.; 2014.

3. WHO. Every Newborn: An Action Plan To End Preventable Deaths. Geneva, Switzerland; 2014. www.who.int/about/licensing 
4. UNICEF. Committing to Child Survival: A Promise Renewe UNICEF Progress Report 2013. New York, USA; 2013. doi:978-92-

15. Nutley T, Gnassou L, Traore M, Bosso AE, Mullen S. Moving data off the shelf and into action: an intervention to improve data-informed decision making
10. doi: 10.3402 .

16. Nutley T. Improving Data Use in Decision Making : An Interventio to Strengthen Health Systems. Chapel Hill, NC; 2012. https://www.

17. Ministry of Health $(\mathrm{MoH})$ [Malawi]. Guidelines for Evidence Use in Policy-Making. Lilongwe, Malawi; 2016. https://www.afidep.

18. UN Every Woman Every Child. UN Commission on Life-Savin Commodities for Women and Children: Commissioners' Report 2012 New York, USA; 2012. https://www.unicef.org/media/files/UN 19. Ministry of Health (MoH) [Malawi]. Malawi Standard Treatmen Guidelines (MSTG) 5th Edition 2015. Incorporating Malawi Essentia Medicines List (MEML) 2015. Lilongwe, Malawi; 2015. http://apps

20. Pronyk PM, Nemser B, Maliqi B, The UN Commission on Life Saving Commodities 3 years on: Global progress update and resul of a multicountry assessment. Lancet Glob Heal. 2016;4(4):e276-e286.

21. Vondal P. USAID Performance Monitoring and Evaluation TIPS: Rapid Appraisal Methods. Washington, D.C.; 2010. http://pdf.usaid gov/pdf_docs/Pnadw105.pdf.

22. Zembe-Mkabile WZ, Jackson D, Sanders D, The "community" in Health Action. 2016;9(1):1-9. doi:10.3402/gha.v9.29177.

23. Gale NK, Heath G, Cameron E, Rashid S, Redwood S. Using the framework method for the analysis of qualitative data in multidisciplinary health research. BMC Med Res Methodol. 2013;13:117. doi:10.1186/1471-2288-13-117.

24. Pope C, Ziebland S, Mays N. Qualitative research in health doi:10.1136/bmj.320.7227.114.

25. Graneheim UH, Lundman B. Qualitative content analysis in nursing research: concepts, procedures and measures to achieve trustworthiness. N
nedt.2003.10.001

26. Ritchie J, Lewis J. Qualitative Research Practice: A Guide for Socia Science Students and Research
doi:10.4135/9781452230108.

27. Ochalek JM, Claxton CP, Revill P, Sculpher MJ, Rollinger A. Supporting the Development of an Essential Health Packge Principles and Initial Assessment for Malawi. York, UK; 2016. https: pure.york.ac.uk/portal/en/publications/supporting-the-developmenof-an-essential-health-package-principles-and-initial-assessment-fomalawi(8198e8f1-e7f5-4518-9127-9a3f5630d6fd).html.

28. Ministry of Health (MoH) [Malawi]. Malawi Health Sector Strategic Plan 2011-2016. Lilongwe, Malawi; 2012. http://www nationalplanningcycles.org/sites/default/files/country_docs/Malawi/2 malawi_hssp_2011_-2016_final_document_1.pdf.

29. UNICEF. Formative Evaluation of UNICEF's Monitoring Results for Equity System (MoRES). MoRES From Evidence to Equity? New York, USA; 2014. https://www.
UNICEF-MoRES_pubs-Main.pdf. Monitoring and Evaluation Practices in the Context of Scaling-up the
Switzerland; 2014. https://www.uhc2030.org/fileadmin/uploads/ihp/ Documents/Country_Pages/Uganda/Uganda strengthening M\%2526 2011 report_final.pd

1. International Health Partnership (IHP). Joint Assessment of Renda 'S Third Health Sector Strategic Plan ( HSSP III). Geneva, Switzerland; 2012. https://www.uhc2030.org/fileadmin/uploads/hih/ Documents/Country_Pages/Rwanda/Joint Assessment of Rwand SSP III. Jun2012.pdf.

32. Paul E. Benin Case Study: Documenting the Results of Implementing Aid Effectiveness Principles in the Health Sector. Geneva, Switzerlan Country_Pages/Benin/benin_case_study_October_2011.pdf.

33. Chaulagai CN, Moyo CM, Koot J, Design and implementation of health management information system in Malawi: Issues, innovation results. Health Policy Plan. 2005;20(6):375-384. doi:10.1093/

34. Nicol E, Bradshaw D, Uwimana-Nicol J, Dudley L. Perception

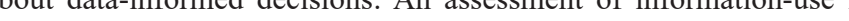
high HiN-prevalence settings in South Africa. BMC Health Serv Res. 2017;17(Suppl 2). doi:10.1186/s12913-017-2641-

5. Mutale W, Chintu N, Amoroso C, Improving health informatio

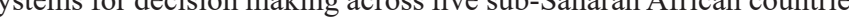
(20)

6. Chilundo B, Sundby J, Aanestad M. Analysing the quality of routine malaria data in Mozambique. Malar J. 2004;3:1-11. doi:10.1186/1475-

37. Piette JD, Lun KC, Moura LA, Impacts of e-health on the outcome of care in low- and middle-income countries: Where do we go from here? Bull World Health Organ. 2012;90(5):365-372. doi:10.247 BLT.11.099069

8. Harrison T, Nutley T. A Review of Constraints to Using Dato for Decision Making: Recommendations to Inform the Design of . org/resources/publications/tr-10-77.

39. Nutley T, Reynolds HW. Improving the use of health data for health system strengthening. Glob Health Action. 2013;6(1):1-10. doi:10.3402/gha.v6i0.20001.

40. Bosch-Capblanch X, Ronveaux O, Doyle V, Remedios V, Bchir A. Accuracy and quality of immunization information systems in doi:10.1111/j.1365-3156.2008.02181.x.

1. Braa J, Heywood A, Sahay S. Improving quality and use of data through data-use workshops: Zanzibar, United Republic of Tanzani-

42. Foreit K, Moreland S LA Data Demand and Information Use in the Health Sector: Conceptual Framework. Chapel Hill, NC, USA: 2006. https://www.measureevaluation.org/resources/publications/ms-06-16 43. Hotchkiss D, Diana M, Foreit K. How Can Routine Health Information System Improve Health System Function in Low-Resource
Setting: Assessing the Evidence Base. Chapel Hill, NC; 2012 htps:/ www.measureevaluation.org/resources/publications/sr-11-65.

44. Smith T. Achieving a Unified System for Monitoring and healthdatacollaborative org/fileadmin/uploads/hdc/Documents Country documents/Achieving Unified_ME_System Malawi_01_April2016_GF_Smith.pdf.

45. Vital Wave. Data Use Partnership: Malawi - Final Report (Unpublished). Palo Alto, CA, USA; 2016

46. Health Data Collaborative. Health Data Collaborative (HDC) Progress Report 2016-2017.; 2017. doi:10.1371/journal.pone.0079777.

.

CA, USA, 2015. http://vitalwave.com/wp-content/uploads/2017/10

48. Development Gateway. Results Data Initiative: Findings from Tanzania. Washington, D.C., USA; 2016. http://www

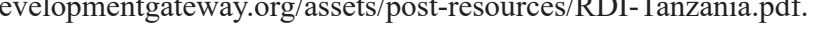

49. USAID/MEASURE. Easing the Data Collection Burden on Healthcare Providers by Strengthening Health Information Systems. publications/tr-17-211_en.

50. Health Metrics Network. Framework and Standards for Country on Systems. Vol 2nd Editio. Geneva, Switzerland; 2008. doi:10.4018/978-1-60566-988-5.

51. Aqil A, Lippeveld T, Hozumi D. PRISM framework: A paradigm shift for designing, strengthening and evaluating routine health informatio
systems. Health Policy Plan. 2009:24(3):217-228. doi:10.1093/heapo systems.
czpo 010 .

52. Ledikwe J, Grignon J, Lebelonyane R, Improving the quality of health information: a qualitative assessment of data management an
eporting systems in Botswana. Heal Res Policy Syst. 2014;12:7. doi:10.1186/1478-4505-12-7.

53. MEASURE Evaluation. PRISM Case Studies : Strengthening and Evaluating RHIS. Chapel Hill, NC, US

54. World Bank Group (WBG), US Agency for International Development (USAID), World Health Organization (WHO). The www who int/hrh/documents/roadmap4health_measurent account/en/. 55. World Bank Group (WBG), US Agency for International Development (USAID), World Health Organization (WHO). Health Action:; 2015, https://live.worldbank.org/sites/default/files/call to action_6-4-15_web.pdf.

56. Gullo S, Galavotti C, Altman L. A review of CARE's Community Score Card experience and evidence. Health Policy Plan.

57. ALMA 2030. RMNCH Country Scorecard Management Too Workshops: October 2013. New York, USA; 2013. http://alma2030. org/sites/default/files/initiatives/mush_workshop_summary
8. Manthalu G. District Health Performance Improvement Evaluatio Report. Lilongwe, Malawi; 2016. https://www.unicef.org/evaldatabase/ files/Evaluation of District Health Performance Improvement Dilawi_2016-003.pdf.

59. Lorenzi NM, Riley RT. Managing Change: An Overview. J Am Med Informatics Assoc. 2000:7(2):116-124 doi:10.1136 jamia.2000.0070116

60. WHO. Quality, Equity, Dignity (QED): A Network for Improving Quality of Care for Maternal, Newborn and Child Health: Monitoring
Framework, Geneva, Switzerland: 2017 . http:/ $/$ www who int/maternal

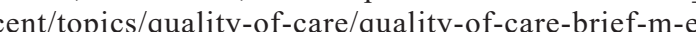
pdf?ua $=1$

61. Tunçalp Ö, Were W, MacLennan C, et al. Quality of care for pregnant women and newborns-the WHO vision. BJOG An Int J Obstet preynant women and newborns-the WHO vision. BJOG An 15 : 1045-1049. doi:10.1111/1471-0528.13451.

62. Green C, de Kock L. How To Guide for Quality Improvement. ohannesburg, South Africa; 2016. https://www.auruminstitute.org improvement/59-guide-for-quality-improvement.

63. Rodríguez DC, Hoe C, Dale EM, et al. Assessing the capacity of ministries of health to use research in decision-making: Conceptual doi:10.1186/s12961-017-0227-3.

64. Clinton Health Access Initiative. Case Study: Improving efficiency and effectiveness of HIV spending through resource mapping in . Using life saving commodities to save lives globally, Lancet Glob Heal. 2016;4(4):e221-e222. doi:10.1016/S2214

66. Althabe F, Belizán JM, McClure EM, et al. A population-based,

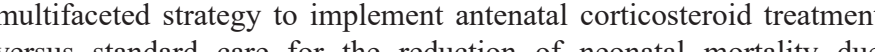
versus standard care for the reduction of neonatal mortality due to preterm birth in low-income and middle-income countries: The doi:10.1016/S0140-6736(14)61651-2. 